\title{
Pressure Sensing Properties of AIN Thin Films Sputtered at Room Temperature
}

\author{
Hye-Won Seok ${ }^{1}$, Sei-Ki Kim ${ }^{1,+}$, Yang-Koo Kang ${ }^{1}$, Youn-Jin Lee ${ }^{1}$, Yeon-Woo Hong ${ }^{1}$, and Byeong-Kwon Ju ${ }^{2}$
}

\begin{abstract}
Aluminum nitride (AIN) thin films with a TiN buffer layer have been fabricated on SUS430 substrate by RF reactive magnetron sputtering at room temperature under $25 \sim 75 \% \mathrm{~N}_{2} /$ Ar. The characterization of film properties were performed using surface profiler, X-ray diffraction, X-ray photoelectron spectroscopy(XPS), and pressure-voltage measurement system. The deposition rates of AIN films were decreased with increasing the $\mathrm{N}_{2}$ concentration owing to lower mass of nitrogen ions than Ar. The as-deposited AIN films showed crystalline phase, and with increasing the $\mathrm{N}_{2}$ concentration, the peak of $\mathrm{AIN}(100)$ plane and the crystallinity became weak. Any change in the preferential orientation of the as-deposited AIN films was not observed within our $\mathrm{N}_{2}$ concentration range. But in the case of $50 \%$ $\mathrm{N}_{2}$ /Ar condition, the peak of (002) plane, which is determinant in pressure sensing properties, appeared. XPS depth profiling of AIN/ TiN/SUS430 revealed Al/N ratio was close to stoichiometric value (45:47) when deposited under 50\% $\mathrm{N}_{2} / \mathrm{Ar}$ atmosphere at room temperature. The output signal voltage of AIN sensor showed a linear behavior between $26 \sim 85 \mathrm{mV}$, and the pressure-sensing sensitivity was calculated as $7 \mathrm{mV} / \mathrm{MPa}$.
\end{abstract}

Keywords: Piezoelectric, AIN thin film, Pressure sensor, RF reactive sputtering, Room temperature deposition

\section{INTRODUCTION}

Over the past decades, pressure sensors such as Si piezoresistive semiconductor based on Si MEMS technology are the most prevalent type of pressure sensor because of its easy integration, high sensitivity, highly befitting for mass production, and they dominate over $83 \%$ of the market share of the pressure sensor [1]. However, its operating temperature has been limited below $573 \mathrm{~K}$, approximately. Therefore an application to combustion pressure sensor for automobile engine such as gasoline direction injection (GDI) type and common rail type, which needs high temperature more than $673 \mathrm{~K}$ and high pressure more than $350 \mathrm{MPa}$, is limited.

Piezoelectric materials have attracted much attention due to their promising properties. Among these materials, Aluminum

${ }^{1}$ Electronic Materials \& Module Team, Korea Institute of Ceramic Engineering \& Technology (KICET)

77, Digital-ro 10-Gil, Guemcheon-gu, Seoul, 153-801, Korea

${ }^{2}$ Department of semiconductor and Nano system, Korea University

145.Anam-ro, Seongbuk-Gu, Seoul, 136-701, Korea

${ }^{+}$Corresponding author: kimseiki@kicet.re.kr

(Received: Mar. 4, 2014, Revised: Mar. 20, 2014, Accepted: Mar. 21, 2014)

This is an Open Access article distributed under the terms of the Creative Commons Attribution Non-Commercial License(http://creativecommons.org/ licenses/bync/3.0) which permits unrestricted non-commercial use, distribution, and reproduction in any medium, provided the original work is properly cited. nitride (AIN) thin film has been widely studied because of its excellent characteristic, which includes the following: the AIN thin film has a high melting point $(2673 \mathrm{~K})$, a high energy band gap $(6.2 \mathrm{eV})$, good thermal conductivity $\left(260 \mathrm{Wm}^{1} \mathrm{~K}^{1}\right)$, a rapid acoustic velocity $(6000 \mathrm{~m} / \mathrm{s})$, extreme hardness, a low acoustic impedance, and good chemical stabilities [2,3]. Especially, AIN thin film is of interest, because of its piezoelectric property at high temperature up to $1423 \mathrm{~K}$ [4]. The piezoelectric property of AlN thin film originates from its oriented crystalline and it has no Curie point. AIN has Wurtzite structure, and the Al-N bond length of the c-axis $(0.498 \mathrm{~nm})$ is longer than that of the a-axis $(0.311 \mathrm{~nm})$. The piezoelectricity of AlN $\left(\mathrm{d}_{33=}=7 \mathrm{pC} / \mathrm{N}\right)$ is originated from the polarization difference in the c-axis direction, and the polarization of AIN is maintained to about $1423 \mathrm{~K}$.

Due to the c-axis orientation tendency of AIN thin film deposited on any substrate materials, the deposition of AIN in thin film type has been carried out by various methods, such as physical vapor deposition, chemical vapor deposition, and molecular beam epitaxy [5-10]. However, techniques such as CVD and MBE require high substrate temperature of above 1273 $\mathrm{K}$ compared with PVD. Thus, PVD methods such as reactive magnetron sputtering are frequently used for the deposition of AIN film because the substrate temperature can be lowered even to room temperature.

Akiyama et al. have reported that they have obtained highly 
oriented AIN thin film by sputtering method at $473 \sim 673 \mathrm{~K}$ and shown its possibility as sensor elements at high temperature [11-13].

In this study, we report on the pressure sensing properties of AIN thin films deposited by RF reactive magnetron sputtering at room temperature.

\section{EXPERIMENTAL}

\subsection{Deposition of thin films}

Thin films were deposited by RF reactive magnetron sputtering (LSS-01, J\&L Tech, Korea) from 5N-grade metal target (Dia. 3") under various ratio of $\mathrm{N}_{2}$ and Ar onto disc-type SUS430 substrate (Dia. $17 \mathrm{~mm}$ ) at room temperature. The SUS430 substrates were washed with acetone, methanol and rinsed in water for 15 minutes by ultrasonic cleaner before deposition in order to remove contaminants. Pre-sputtering was performed for 10 minutes to remove any contamination on the target. The base vacuum level of deposition chamber was lower than $0.9 \mathrm{mPa}$,

In our preliminary experiments, it was confirmed that direct deposition of AIN films to SUS430 resulted in excessive stress and resultant cracks in the AIN films owing to the large difference in thermal expansion coefficients between SUS430 $(\sim 10.4 \mathrm{ppm} / \mathrm{K})$ and $\operatorname{AlN}(4.9 \mathrm{ppm} / \mathrm{K})$. To avoid the cracks in the AIN thin films, it is necessary to insert buffer layer, which has the intermediate thermal expansion coefficient between SUS430 as a substrate and AIN. And the buffer layer must be conductive in order to use as an electrode. Titanium nitride (TiN), which has an appropriate thermal expansion coefficient $(\sim 9.4 \mathrm{ppm} / \mathrm{K})$ and metallic property, was selected as the buffer layer. TiN films with a thickness of $\sim 400 \mathrm{~nm}$ were deposited under $25 \% \mathrm{~N}_{2} / \mathrm{Ar}$ at room temperature. After the deposition of TiN as a buffer layer, $150 \mathrm{~nm}$-thick AIN films were deposited onto the TiN buffer layer. The $\mathrm{N}_{2} / \mathrm{Ar}$ ratio in the chamber was varied to $25 \sim 75 \%$ at room temperature.

The specific deposition conditions of TiN and AIN films are shown in Table 1.

Table 1. Deposition conditions of TiN and AIN

\begin{tabular}{lcc}
\hline \multicolumn{1}{c}{ Item } & TiN & AlN \\
\hline Target & $\mathrm{Ti}$ & $\mathrm{Al}$ \\
Power & 3 & 2 \\
Working Pressure[Pa] & 0.6 & 0.3 \\
Atmosphere $[\%]$ & $25 \% \mathrm{~N}_{2} / \mathrm{Ar}$ & $25 \sim 75 \% \mathrm{~N}_{2} / \mathrm{Ar}$ \\
Substrate temp. $[\mathrm{K}]$ & R.T. & R.T. \\
\hline
\end{tabular}

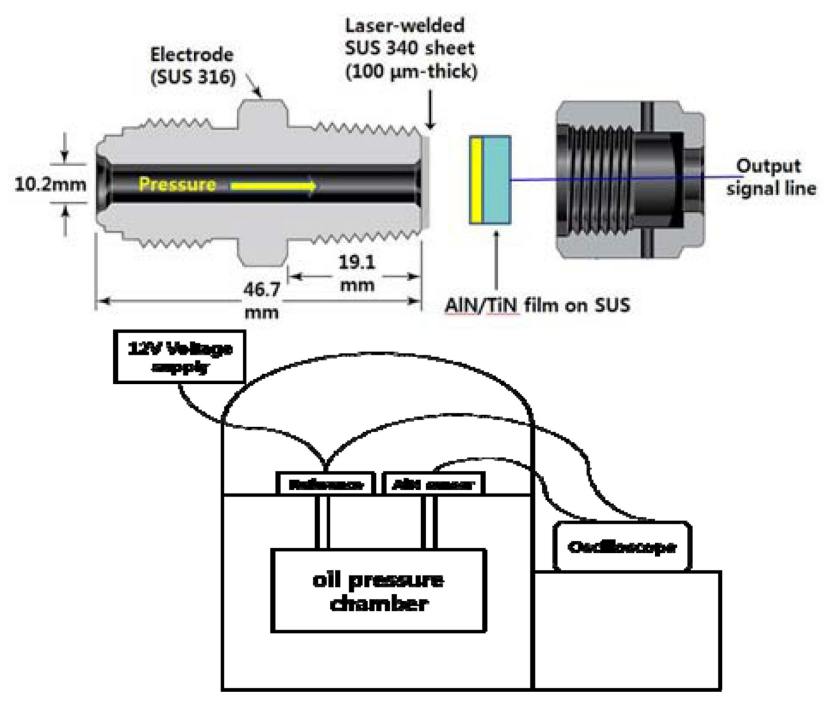

Fig. 1. Cross section of pressure-sensing module and schematic diagram of oil pressure application apparatus.

\subsubsection{Characterization}

Thickness and deposition rate of AIN thin films were measured with a surface profiler (Alpha step 500, Tencor, USA). Crystalline phases of the films were confirmed using X-ray diffraction at $10 \mathrm{o}$ to 70o (Rigaku DMAX2200, Japan, Cu Ká, 40 kV/30 mA). The depth profiling along to the deposition direction was performed using XPS.

The evaluation of pressure-sensing properties was performed using an oil pressure application apparatus with a reference sensor (UNIK5000, GE, USA), whose output signal range was $0 \sim 5 \mathrm{~V}$ with the accuracy of $\pm 0.04 \%$ FS. The AIN-coated SUS430 discs were implemented into pressure-sensing modules. We sandwiched $\mathrm{Cu}$ foil (dia=13 mm) as the top electrodes between AlN thin film and laser-welded SUS sheet, and the modules were installed into pressure application apparatus as depicted in Fig.1. The range of the applied pressure was $1 \sim 10 \mathrm{MPa}$ with a frequency of $2 \mathrm{~Hz}$.

\section{RESULTS AND DISCUSSIONS}

The deposition rates of AIN films deposited by RF reactive magnetron sputter were decreased from $1.8 \mathrm{~nm} / \mathrm{min}$ to $1.1 \mathrm{~nm} / \mathrm{min}$ with increasing the $\mathrm{N}_{2}$ concentration from $25 \%$ to $75 \%$ in the deposition chamber. This result can be explained by the difference in the bombardment energy of Argon and Nitrogen ions based on the difference in the mass of Argon and Nitrogen ions to bombard $\mathrm{Al}$ target. The mass of $\mathrm{Ar}$ (molecular weight 40) is heavier than that of $\mathrm{N}_{2}$ (molecular weight 14), and the resultant sputtering yield 
AIN-SUS 430

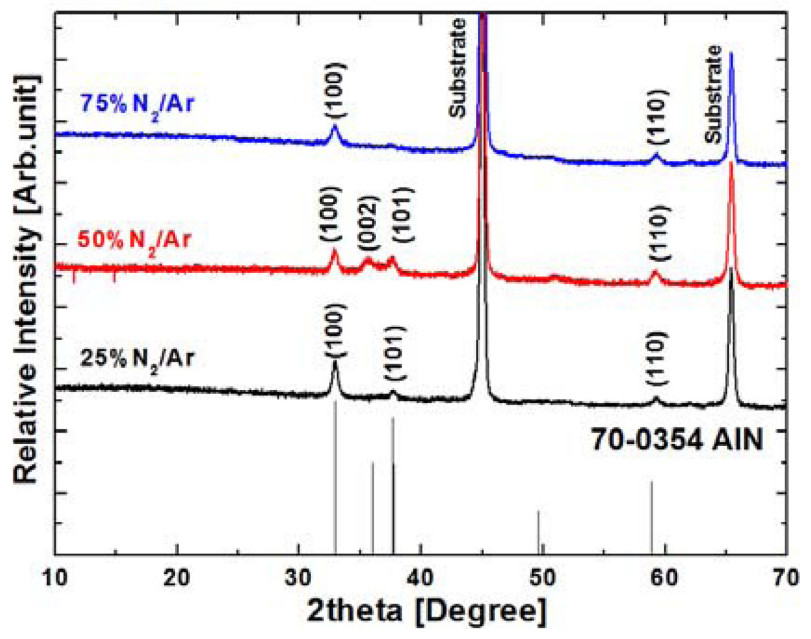

Fig. 2. XRD patterns of AIN thin films on SUS430 at various $\mathrm{N}_{2} / \mathrm{Ar}$ ratio.

of $\mathrm{Ar}$ is higher than those of that of Nitrogen ion. Therefore, the increase in the $\mathrm{N}_{2}$ concentration results in the decrease in $\mathrm{Al}$ sputtering yield. In addition, a nitride reaction of the target surface was increased with increasing $\mathrm{N}_{2}$ concentration, and the sputtering yield of the target was decreased with increasing the nitride on the target surface. The binding energies of AIN and $\mathrm{Al}$ are $9.1 \mathrm{eV}$, and $3.35 \mathrm{eV}$, respectively. Thus the sputtering yield of AIN is lower than that of $\mathrm{Al}[14]$.

Fig. 2 shows X-ray diffraction (XRD) patterns of AIN thin films deposited at room temperature under different $\mathrm{N}_{2}$ concentrations. As-deposited AIN films showed crystalline phase, and with increasing the $\mathrm{N}_{2}$ concentration, the peak of AIN(100) plane and the crystallinity became weak. The peaks of (100), (101) planes were observed at the $25 \% \mathrm{~N}_{2}$ concentration. With increasing $\mathrm{N}_{2}$ concentration to $50 \%$, the peak of (002) plane appeared. At the $75 \% \mathrm{~N}_{2}$ concentration, the peak of (002) plane was decreased. These results can be explained by the reaching particle energy on the growth surface and the difference of the $\mathrm{Al}, \mathrm{N}$ composition. The AIN thin film at $25 \% \mathrm{~N}_{2} / \mathrm{Ar}$ ratio is grown with (100) planes owing to the excess of $\mathrm{Al}$ atom by high sputtering yield. At $75 \%$ $\mathrm{N}_{2} /$ Ar ratio, the intensity of (002) plane was decreased by the excess of nitrogen gas and a low kinetic energy of the reaction particles. In the high $\mathrm{N}_{2}$ concentration, the kinetic energy of the sputtered particles is low because kinetic energy of Ar is mainly used as the generating and accelerating of the secondary electrons by the accumulation of target nitrification [15-17]. So, it is thought to be appropriate that AIN thin films are deposited in $\mathrm{N}_{2}$ gas concentration of in the region $50 \%$ approximately [18].

Fig. 3 shows the depth profiling by XPS along to the deposition

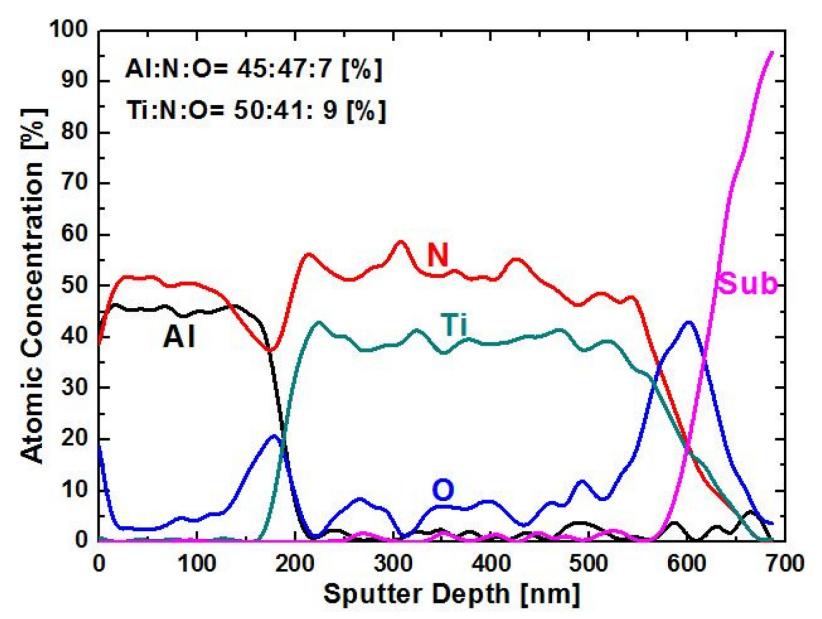

Fig. 3. XPS depth profiling of AIN/TiN/SUS430 deposited under $50 \% \mathrm{~N}_{2} / \mathrm{Ar}$ atmosphere at room temperature.

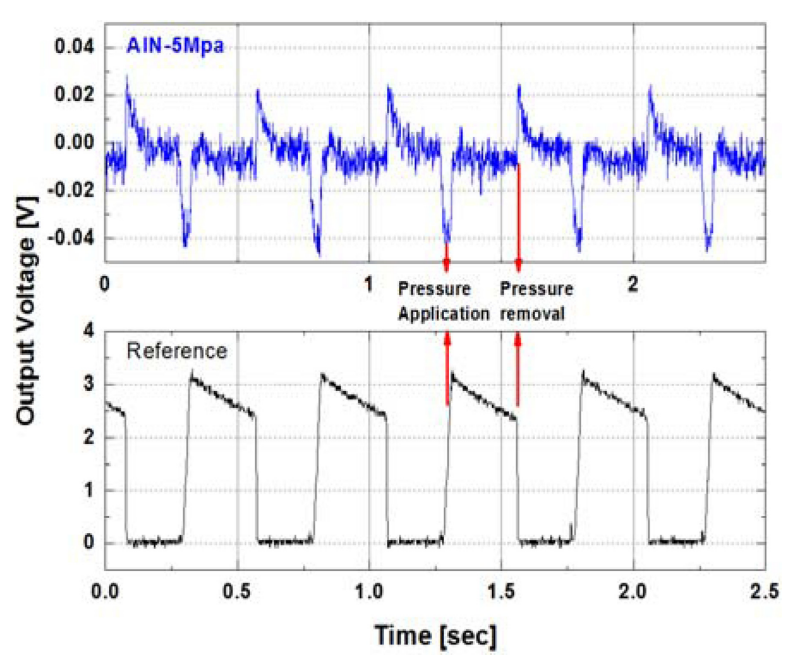

Fig. 4. Pressure sensing behavior of AlN sensor module composed of AlN thin films (@5 MPa).

direction. The XPS depth profiling of AIN thin film with a TiN buffer layer on SUS430 substrate revealed $\mathrm{Al} / \mathrm{N}$ ratio was close to stoichiometric value $(45: 47)$ when deposited under $50 \% \mathrm{~N}_{2} / \mathrm{Ar}$ atmosphere at room temperature. Oxygen component is observed from surface to about $30 \mathrm{~nm}$ in depth, and somewhat high ratio of oxygen in the boundary of AlN/TiN and TiN/substrate is thought to be caused by target exchange. Ti $/ \mathrm{N}$ ratio showed $\mathrm{Ti}$ excess (50:41) Titanium has similar thermal expansion coefficient $(\sim 8.6$ $\mathrm{ppm} / \mathrm{K}$ ) and electrical conductivity to TiN. Therefore, it is thought that there are little effects on the properties of AIN films.

Fig. 4 shows the pressure sensing behavior of AIN sensor module deposited under $50 \% \mathrm{~N}_{2} / \mathrm{Ar}$ atmosphere. The applied pressure was $5 \mathrm{MPa}$ with a frequency of $2 \mathrm{~Hz}$. The output signal voltage of the reference sensor showed about $3 \mathrm{~V}$, and that of AIN 


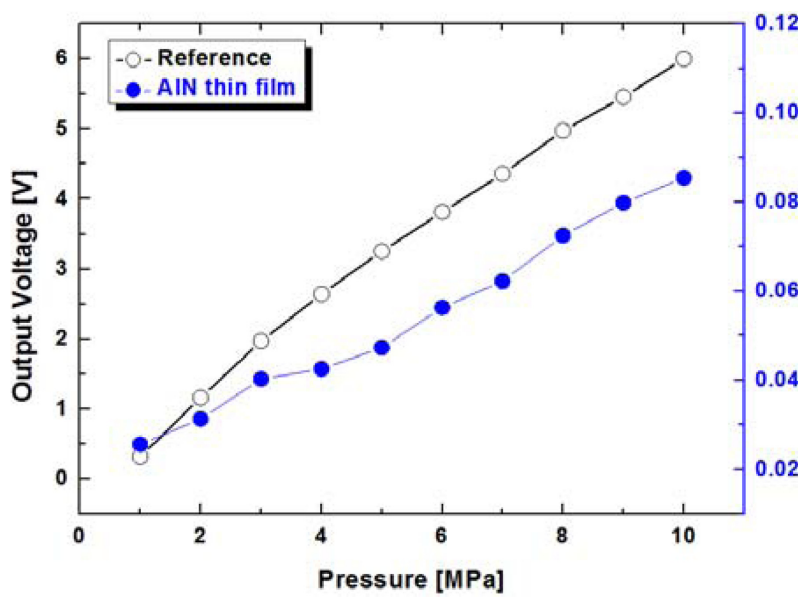

Fig. 6. Pressure sensing characteristics of AlN sensor $\left(50 \% \mathrm{~N}_{2} / \mathrm{Ar}\right)$.

sensor module appears at the moment of pressure application and removal with a pulse pattern. Unlike Si piezo-resistive sensor, the piezoelectric properties of AIN are produced by a change in the polarization in the c-axis direction originated from a change in the Al-N bond length. Therefore, the pressure-induced output voltage of AIN thin film appears at the moment of pressure application and removal. Electrical charge of dipole of AIN is changed when the dipole shrink (pressure application) and expand (pressure removal). The output signal voltage showed about $43 \mathrm{mV}$ with a rapid-respond and reproducible pattern.

If we consider the output signal of commercial reference sensor is generated through a noise-cut and amplifying circuit, the output signal of AIN thin film sensor fabricated in this work without any circuit shows very distinct and reproducible output signal voltage, and a possibility as a pressure sensing element for high temperature and high pressure use.

Fig. 5 shows pressure sensing characteristics of a commercial reference sensor and AIN sensor fabricated in this work in the pressure range 1 10 $\mathrm{MPa}$. The output signal of AIN sensor showed a linear behavior between $26 \sim 85 \mathrm{mV}$, and that of the reference sensor showed $0.3 \sim 6 \mathrm{~V}$. The pressure-sensing sensitivities of AIN and reference sensor were calculated as $7 \mathrm{mV} / \mathrm{MPa}$ and $0.6 \mathrm{~V} /$ Mpa, respectively.

\section{CONCLUSIONS}

In this research, aluminum nitride (AIN) thin films with a TiN buffer layer have been fabricated on SUS430 substrate by RF reactive magnetron sputtering at room temperature under $25 \sim 75 \%$ $\mathrm{N}_{2} /$ Ar. The deposition rates of AIN films were decreased from
$1.8 \mathrm{~nm} / \mathrm{min}$ to $1.1 \mathrm{~nm} / \mathrm{min}$ with increasing the $\mathrm{N}_{2}$ concentration owing to the lower mass of nitrogen ions than Ar. The asdeposited AIN films showed crystalline phase, and increase in the $\mathrm{N}_{2}$ concentration resulted in the weak crystallinity. Any change in the preferential orientation of the as-deposited AIN films was not observed within our $\mathrm{N}_{2}$ concentration range. But in the case of $50 \% \mathrm{~N}_{2} / \mathrm{Ar}$ condition, the peak of (002) plane, which is determinant in pressure sensing properties, appeared. XPS depth profiling of $\mathrm{AIN} / \mathrm{TiN} / \mathrm{SUS} 430$ revealed $\mathrm{Al} / \mathrm{N}$ ratio was close to stoichiometric value (45:47) when deposited under 50\% $\mathrm{N}_{2} / \mathrm{Ar}$ atmosphere at room temperature. The output signal voltage of AlN sensor showed a linear behavior between $26 \sim 85 \mathrm{mV}$, and the pressure-sensing sensitivity was calculated as $7 \mathrm{mV} / \mathrm{MPa}$.

The output signal of AIN thin film sensor fabricated in this work showed very distinct and reproducible output signal voltage, and a possibility as a pressure sensing element for high temperature and high pressure use.

\section{REFERENCES}

[1] T. Sugimoto, "Annual report of Japanese ceramic industry 2002”, Ceramics Japan, vol. 38, pp. 686-693, 2003.

[2] C. Ozgit, I. Donmez, M. Alevli, and N. Biyikli, "Self-limiting low-temperature growth of crystalline AIN thin films by plasma-enhanced atomic layer deposition", Thin Solid Films, vol. 520, pp. 2750-2755, 2012.

[3] Z. An, C. Men, Z. Xu, P. K. Chu, and C. Lin, "Electrical properties of AIN thin films prepared by ion beam enhanced deposition", Surf. Coat. Technol., vol. 196, pp. 130134, 2005.

[4] R. C. Turner, P. A. Fuierer, R. E. Newnham, and T. R. Shrout, "Materials for high temperature acoustic and vibration sensors: a review", Appl. Acoust.., vol. 41, pp. 299-324, 1994.

[5] B. C. Ko and C. W. Nam, "Optimum deposition conditions of AIN thin film on the Si substrate for SAW application", J. Sensor. Sci. \& Tech., vol. 16, no. 4, pp. 301-306, 2007.

[6] E. Rille, R. Zarwasch, and H. K. Pulker, "Properties of reactively dc-magnetron-sputtered AIN thin films", Thin Solid Films., vol. 228, p. 215, 1993.

[7] X. Song, R. Fu, and H. He, "Frequency effects on the dielectric properties of AIN film deposited by radio frequency reactive magnetron sputtering", Microelec. Eng., vol. 86, pp. 2217-2221, 2009.

[8] N. Matsunami, T. Shimura, M. Tazawa, T. Kusumori, H. Kakiuchida, M. Ikeyama, Y. Chimi, and M. Sataka, "Modifications of AIN thin films by ions", Nucl. Instru m. Methods B., vol. 257, pp. 433-437, 2007.

[9] R. Boichot, A. Claudel, N. Baccar, A. Milet, E. Blanquet, and M. Pons, "Epitaxial and polycrystalline growth of AIN by high temperature CVD: Experimental results and simulation", Surf. Coat. Technol., vol. 205, pp. 1294-1301, 
2010 .

[10] B. Liu, Q. M. Fu, K. M. Wu, and C. Liu, "Studies of growth method and properties of AIN grown by RF-MBE", J. Kor. Phys. Soc., vol. 52, pp. S17-S19, 2008.

[11] M. Akiyama, T. Harada, C. N. Xu, K. Nonaka, and T. Watanabe, "Preparation of highly orientated AIN thin films on glass substrates by helicon plasma sputtering and design of experiments", Thin Solid Films, vol. 350, pp. 85-90, 1999.

[12] M. Akiyama, C. N. Xu, M. Kodama, I. Usui, K. Nonaka, and T. Watanabe, "Preparation of highly orientated aluminum nitride thin films on polycrystalline substrates by helicon plasma sputtering and annealing”, J. Amer. Cer. Soc., vol. 84, pp. 1917-1920, 2001.

[13] M. Akiyama and N. Ueno, "Preparation and application of highly orientated aluminum nitride thin film-ceramic skin", Bull. Ceram. Soc. Jpn., vol. 39, pp. 696-699, 2004.

[14] J. B. Malherbe, "Sputtering of compound semiconductor surfaces. I. Ion-solid interactions and sputtering yields",
Crit. Rev. Sol. State. Mater. Sci., vol. 19, no. 2, pp. 55-127, 1994.

[15] H. P. Loebl, M. Klee, C. Metzmacher, W. Brand, R. Milsom, and P. Lok, "Piezoelectric thin AIN films for bulk acoustic wave (BAW) resonators", Mater. Chem. Phys., vol. 79, p. 143, 2003.

[16] J. H. Bang, D. H. Chang, S. J. Kang, D. G. Kim, and Y. S. Yoon, "Orientation, surface roughness and piezoelectric characteristics of AIN thin films with RF magnetron sputtering conditions", Inst. Electron. Inf. Eng., vol. 43, pp. 247253, 2006.

[17] M. Ishihara, S.J. Li, H. Yumoto, K. Akashi, and Y. Ide, "Control of preferential orientation of AIN films prepared by the reactive sputtering method", Thin solid film., vol. 316, pp. 152-157, 1998

[18] X. H. Xu, H. S. Wu, C. J. Zhang, and Z. H. Jin, "Morphological properties of AIN piezoelectric thin films deposited by DC reactive magnetron sputtering", Thin Solid Films., vol. 388, pp. 62-67, 2001. 